\title{
DE L'ACTION MUTAGÉNE DES RAYONS GAMMA SUR LES LACTOBACILLES
}

\author{
par \\ R. DONIKIAN, L. R. VALETTE et G. DE SAINT-AUBERT \\ Institut Merieux, 69-Marcy l'Etoile
}

\section{Introduction}

Les lactobacilles jouissent depuis une vingtaine d'années d'un regain d'intérêt [3] en thérapeutique, alors qu'ils sont utilisés depuis des siècles en diététique et dans la préparation de produits alimentaires tels que yaourts, laits fermentés, fromages, etc.

Cet intérêt des lactobacilles est dû aux facteurs suivants :

1) Les lactobacilles sont des microorganismes parfaitement inoffensifs et sont les hôtes normaux du tube intestinal, du moins au cours des premières années de la vie [10].

2) En raison de l'orientation de la thérapeutique vers l'emploi de plus en plus fréquent d'antibiotiques, on a été amené à étudier des germes capables d'acquérir une antibiorésistance polyvalente et de prévenir ainsi par leur implantation, les troubles gastrointestinaux survenant en cours de traitement. Parmi les différents microorganismes, les lactobacilles se sont montrés particulièrement aptes à acquérir ce caractère d'antibiorésistance et à remplir le rôle de complément à toute antibiothérapie.

Ceci explique notre choix des lactobacilles et l'étude de la possibilité de fixer par des rayons gamma ce caractère antibiorésistant, jusque-là phénotypique et par conséquent soumis à des variations.

Si, jusqu'à présent, les rayons gamma ont été utilisés soit dans l'irradiation stérilisante des germes [4], soit dans l'étude des modifications génétiques provoquées sur des germes du groupe des Enterobacteriacées, il semble que peu de travaux ont été effectués sur la fixation des caractères acquis des bactéries tels que les lactobacilles $[5,6,7]$.

\section{Matériel et méthodes}

\section{A) Matériel}

Notre expérimentation a porté au début sur le variant tétracyclino-résistant du lactobacillus casei désigné ici par le symbole 
casei Te. Pour l'irradiation, des cultures de 24 heures de Casei Te en milieu M.R.S. (1) ont été utilisées. L'irradiation a porté sur la culture, sur les germes centrifugés et repris soit par de l'eau physiologique soit par du tampon phosphate à $p \mathbf{H} \mathbf{6 , 4}$.

Dans tous les cas, la suspension bactérienne renferme un agent inducteur qui est une base purique, à la concentration de $1,5 \mathrm{p}$. 1000 et l'antibiotique correspondant. Dans la première expérience, la tétracycline a été utilisée à deux concentrations différentes :

$\mathrm{Al}$, soit $50 \mathrm{mg}$ de tétracycline pour $10 \mathrm{ml}$ de culture.

$\mathrm{A} 2$, soit $100 \mathrm{mg}$ de tétracycline pour $10 \mathrm{ml}$ de culture.

\section{B) L'irradiation}

De nombreux travaux, dont ceux de Dupuy $[5,6,7]$, ont fixé les conditions de stérilisation du lait et de destruction des lactobacilles. Les doses de rayons gamma vont de 10 à 150 kilorads.

Notre but étant de provoquer une mutation stable au sein d'une population de lactobacilles et non de les détruire, il fallait déterminer la dose d'irradiation de rayons gamma la plus satisfaisante. Grâce à l'amabilité du C.L.A.A., nous avons pu étudier les effets de deux sources d'irradiation :

1) L'une à faible débit de dose ;

2) L'autre à fort débit de dose.

\section{Irradiation à faible débit}

Il s'agit d'un irradiateur CEA-Conservatome du type "Aurore ».

La chambre d'irradiation est cylindrique, le volume utile offrant la meilleure homogénéité de flux présente un diamètre de $70 \mathrm{~mm}$ pour une hauteur de $150 \mathrm{~mm}$.

La source est constituée par 5 crayons de $20 \mathrm{~cm}$ de hauteur, de cobalt 60 .

Les crayons sont disposés sur le pourtour de la chambre d'irradiation à égale distance l'un de l'autre.

Les échantillons à irradier sont introduits dans un évidement situé à la partie centrale du cylindre. Au moment des expériences le débit de dose était de 44 kilorads/heure.

\section{Irradiation à fort débit}

La source de cobalt 60 du C.L.A.A., est constituée par un cylindre dont le diamètre peut varier entre les limites usuelles suivantes : $25 \mathrm{~cm}$ et $50 \mathrm{~cm}$. Les débits de dose étant respectivement de 2,5

(1) De Mann Rogosa et Sharpe, J. Appl. Bact., 1960, 23, 130. 
TABLEAU I

Irradiation a faible débit du L. Casei Te

\begin{tabular}{|c|c|c|c|c|c|}
\hline $\begin{array}{c}\text { Dose de } \\
\text { Tétracycline } \\
\text { en } m g / m l\end{array}$ & $\begin{array}{c}\text { Dose } \\
\text { d'irradiation } \\
\text { en } M R\end{array}$ & Durée & En milieu de culture & En tampon & En eau physiologique \\
\hline Al & $\begin{array}{l}0,11 \\
0,45 \\
0,90\end{array}$ & $\begin{array}{l}12 \mathrm{~h} 30 \\
10 \mathrm{~h} \\
20 \mathrm{~h}\end{array}$ & $\begin{array}{l}\text { Nombreuses colonies } \\
\text { autour des disques } \\
\text { Absence de culture } \\
\text { Absence de culture }\end{array}$ & $\begin{array}{l}\text { Nombreuses colonies } \\
\text { autour des disques } \\
\text { Absence de culture } \\
\text { Absence de culture }\end{array}$ & $\begin{array}{l}\text { Nombreuses colonies } \\
\text { autour des disques } \\
\text { Absence de culture } \\
\text { Absence de culture }\end{array}$ \\
\hline 10 & $\begin{array}{l}0,11 \\
0,45 \\
0,90\end{array}$ & $\begin{array}{l}2 \mathrm{~h} 30 \\
10 \mathrm{~h} \\
20 \mathrm{~h}\end{array}$ & $\begin{array}{l}\text { Quelques colonies } \\
\text { autour des disques } \\
\text { Absence de culture } \\
\text { Absence de culture }\end{array}$ & $\begin{array}{l}\text { Quelques colonies } \\
\text { autour des disques } \\
\text { Absence de culture } \\
\text { Absence de culture }\end{array}$ & $\begin{array}{l}\text { Absence de culture } \\
\text { Absence de culture } \\
\text { Absence de culture }\end{array}$ \\
\hline
\end{tabular}


TABLEAU II

Irradiation a FORT débit du L. Casei Te

\begin{tabular}{|c|c|c|c|c|c|}
\hline $\begin{array}{c}\text { Dose de } \\
\text { Tétracycline } \\
\text { en } \mathrm{mg} / \mathrm{ml}\end{array}$ & $\begin{array}{c}\text { Dose } \\
\text { d'irradiation } \\
\text { en } M R\end{array}$ & $\begin{array}{l}\text { Durée } \\
\text { en mn }\end{array}$ & En milieu de culture & En tampon & En eau physiologique \\
\hline Al & $\begin{array}{l}0,1 \\
0,4 \\
0,8\end{array}$ & $\begin{array}{r}8 \\
32 \\
64\end{array}$ & $\begin{array}{c}\text { Faible culture } \\
\text { Rien autour des disques } \\
\text { Absence de culture } \\
\text { Absence de culture }\end{array}$ & $\begin{array}{c}\text { Faible culture } \\
\text { Rien autour des disques } \\
\text { Absence de culture } \\
\text { Absence de culture }\end{array}$ & $\begin{array}{c}\text { Faible culture } \\
\text { Rien autour des disques } \\
\text { Absence de culture } \\
\text { Absence de culture }\end{array}$ \\
\hline $\mathrm{A} 2$ & $\begin{array}{l}0,1 \\
0,4 \\
0,8\end{array}$ & $\begin{array}{r}8 \\
32 \\
64\end{array}$ & $\begin{array}{l}\text { Absence de culture } \\
\text { Absence de culture } \\
\text { Absence de culture }\end{array}$ & $\begin{array}{c}\text { Faible culture } \\
\text { Rien autour des disques } \\
\text { Absence de culture } \\
\text { Absence de culture }\end{array}$ & $\begin{array}{c}\text { Faible culture } \\
\text { Rien autour des disques } \\
\text { Absence de culture } \\
\text { Absence de culture }\end{array}$ \\
\hline
\end{tabular}


TABLEAU III

COURBE DE CROISSANCE ENREGISTRÉE AU BIOPHOTOMÈTRE DE JOUAN

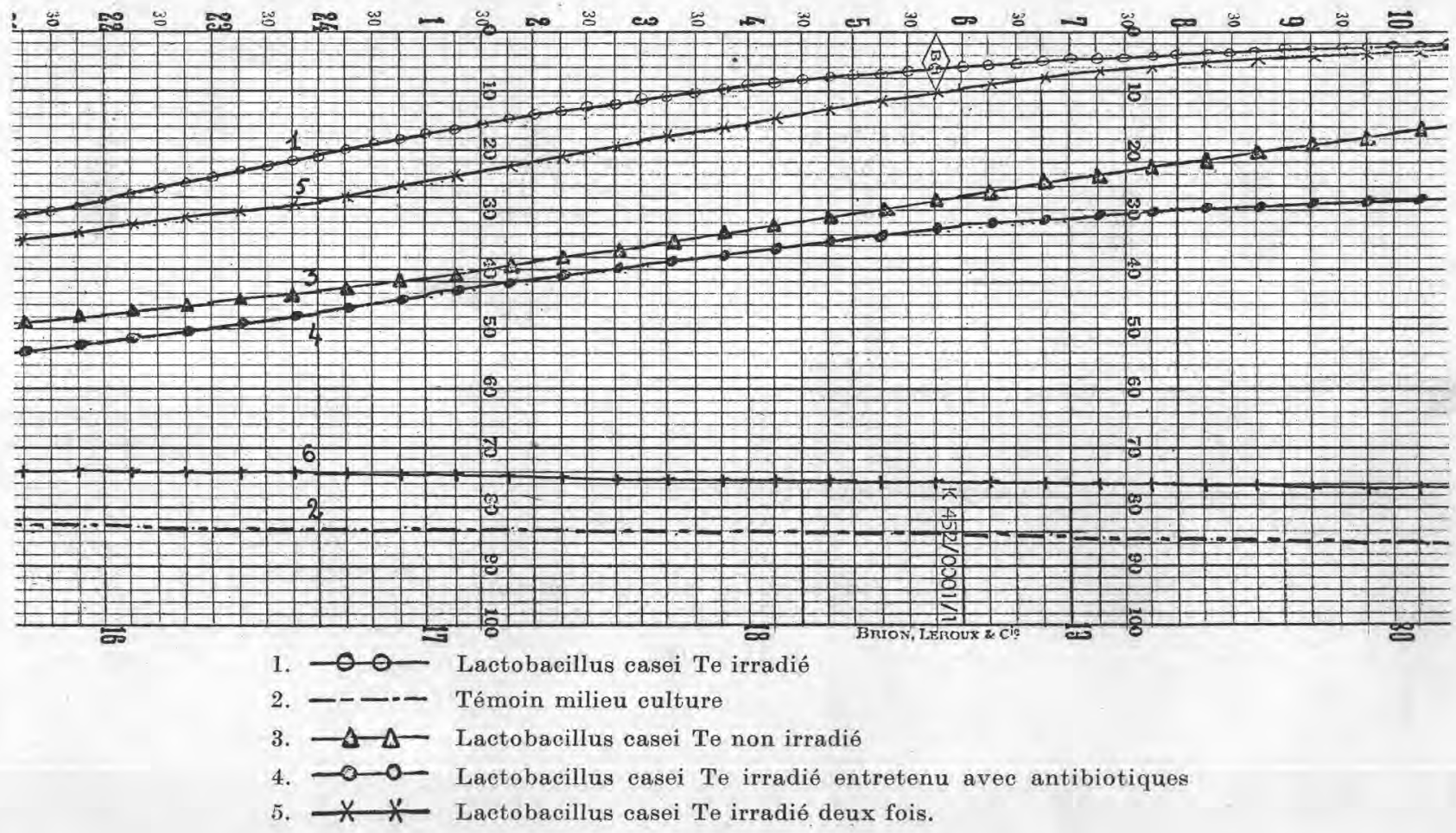


TABLEAU IV

ANTIbIorésistance COMParÉe DES SOUChes

\begin{tabular}{|c|c|c|c|c|c|}
\hline \multirow{2}{*}{$\begin{array}{l}\text { Concentration } \\
\text { en Tétracycline } \\
\text { des disques } \\
(\text { en } m \mathrm{cg})\end{array}$} & \multicolumn{5}{|c|}{ Zone d'inhibition en millimètres } \\
\hline & $\begin{array}{c}\text { Souche } L \text { Casei Te } \\
\text { non irradiée } \\
\text { entretenue } \\
\text { avec antibiotiques }\end{array}$ & $\begin{array}{c}\text { Souche Casei } \\
\text { non irradiée } \\
\text { entretenue } \\
\text { sans antibiotiques }\end{array}$ & $\begin{array}{c}\text { Souche irradiée } \\
\text { entretenue } \\
\text { avec antibiotiques }\end{array}$ & $\begin{array}{c}\text { Souche irradiée } \\
\text { sans antibiotiques } \\
\text { (30 passages) }\end{array}$ & $\begin{array}{c}\text { Souche irradiée } \\
\text { deux fois }\end{array}$ \\
\hline $\begin{array}{r}1000 \\
500 \\
250 \\
100 \\
50\end{array}$ & $\begin{array}{c}28 \\
21 \\
20 \\
14 \\
\text { Résistant }\end{array}$ & $\begin{array}{c}\text { Devient très } \\
\text { rapidement sensible } \\
\text { (30 mm à toutes } \\
\text { les concentrations) }\end{array}$ & $\begin{array}{c}25 \\
20 \\
16 \\
14 \\
\text { Résistant }\end{array}$ & $\begin{array}{c}28 \\
22 \\
19 \\
14 \\
\text { Résistant }\end{array}$ & $\begin{array}{c}21 \\
22 \\
20 \\
14 \\
\text { Résistant }\end{array}$ \\
\hline
\end{tabular}


et 1,5 megarads à l'heure, au centre du cylindre. Cette source est constituée par une centaine de barreaux de cobalt 60 .

Lors des expériences, le débit horaire était de 750 kilorads.

\section{C) Méthode d'isolement des mutants}

Dans cette culture irradiée, il s'agit d'isoler ensuite les mutants les plus actifs; la technique en est la suivante :

Aussitôt après irradiation, les cultures sont réparties sous un volume de $1 \mathrm{ml}$ dans des boîtes de Pétri stériles puis de la gélose MRS fondue et ramenée à la température de $40^{\circ}$ est versée dans la boîte de Pétri $[8,9,11]$. Après mélange et prise en masse de la gélose, des disques d'antibiotiques aux concentrations suivantes : 1000 gamma, 500 gamma, 250 gamma, 100 et 50 gamma, sont disposés sur la surface. Ces boîtes sont mises ensuite à incuber à $37^{\circ} \mathrm{C}$ durant trois jours. Nous notons alors si la culture a résisté à la dose d'irradiation, et si le développement a lieu au niveau des disques d'antibiotiques. Ce dernier point nous intéresse surtout [1 et 2] car le germe est prélevé à ce niveau et ensemencé dans du milieu de culture neuf.

\section{Résultats}

Les tableaux I et II montrent l'influence de l'intensité de l'irradiation sur la survie et l'antibiorésistance du Lactobacillus casei tétracyclino-résistant.

D'après les résultats relevés sur ces tableaux, il est manifeste que l'action la plus nette est obtenue avec l'irradiateur à faible débit à la dose de 110 kilorads et à la concentration $\mathrm{Al}$ de tétracycline, soit $5 \mathrm{mg}$ par ml. Par la suite, nos études ont porté sur la souche TAI/LO, 11. Cette souche a subi une trentaine de passages sur milieu MRS puis elle a été étudiée quant à son antibiorésistance et à sa vitalité vis-à-vis de la souche de départ non irradiée. De plus, nous avons voulu voir si une seconde irradiation à 120 kilorads à faible débit, pouvait améliorer l'antibiorésistance et la faire passer à un niveau supérieur.

Les tableaux III et IV montrent les résultats obtenus.

Ces tableaux montrent que :

1) La multiplication de la souche easei Te irradiée une fois est excellente et même supérieure à la souche de départ.

2) L'antibiorésistance de la souche est acquise et se maintient après trente subcultures en absence d'antibiotiques.

3) Une seconde irradiation semble améliorer l'antibiorésistance et la faire monter à un niveau supérieur. Mais nos résultats ne sont pas encore très probants. Nous poursuivons actuellement cette 
expérimentation sur d'autres lactobacilles et streptocoques. Elle fera l'objet d'une communication ultérieure.

En conclusion de cette étude sur les lactobacilles, il se dégage les points suivants :

a) Les lactobacilles sont sensibles aux fortes radiations ionisantes. Les doses limites d'irradiation sont de 100 kilorads;

b) L'action mutagène la plus nette a été obtenue à partir d'une source de rayons gamma à flux lent, débitant 100000 rads en 2 à 3 heures.

c) Pour obtenir une mutation dans un sens dirigé sous l'action des rayons gamma, il est nécessaire d'avoir déjà des germes sélectionnés, les rayons gamma fixant le caractère phénotypique et le faisant entrer dans le génotype. Les mutants ainsi obtenus semblent dans nos expérimentations en cours, depuis lors, génétiquement stabilisés. Il serait donc possible d'obtenir des souches de lactobacilles antibiorésistants, sans avoir recours à une sélection continue.

\section{Résumé}

Cette étude porte sur des lactobacilles utilisés en thérapeutique pour leurs caractères antibiorésistants, dans la prévention de certains troubles gastro-intestinaux. La possibilité de fixer par les radiations gamma ce caractère d'antibiorésistance jusque-là phénotypique donc soumis à des variations, a été étudiée. Il résulte de ce travail que les lactobacilles sensibles aux radiations ionisantes à partir de 200 kilorads, peuvent présenter des mutations lorsqu'ils sont soumis à des doses de 80 à 100 kilorads. Pour obtenir des mutants génétiquement stabilisés, il convient d'irradier des bactéries déjà sélectionnées envers le caractère désiré.

\section{Summary}

Mutagen action of gamma radiation upon lactobacillus :

This communication concerns a species of Lactobacillus employed in therapeutics for their antibioresisting characters in the prevention of some gastro-intestinal diseases. We study the possibility of fixing by gamma radiation this character of antibioresistance; this character was untill now phenotypical, therefore subjected to variations. From this study, it appears that the lactobacillus, which are sensible to ionizing radiations from 200 kilorads, may present some mutation when they are subjected to doses of 80 to 100 kilorads. To obtain mutants genetically stabilized, we must irradiate bacteria previously selected against the wanted character. 


\section{BIBLIOGRAPHIE}

[1] Adelberg (E.) et Pittard (J.). Chromosome transfer in bacterial conjugation. Bact. Reviews, 1965, 29 (2), 161.

[2] Baudens (J. G.) et Chabbert (Y. A.). Analyse des facteurs de résistance transférables isolés en France. Ann. Inst. Pasteur, 1967, 112, 565.

[3] Dubos (R.). Le rôle biologique de la flore digestive. Rev. d'Immunologie, 1962, 26 (3), 97.

[4] De Saint-Aubert (G.), Valette (L.), Plan (R.) et Cherby (D.). Essais d'exposition aux radiations gamma de petits articles médicaux et de solutions protéiniques pharmaceutiques. Radiostérilization of Medical Product I.A.E.A., Vienne, 1967.

[5] Dupux (P.) et Tremeau (O.). Influence des conditions de culture sur la résistance aux radiations de quelques lactobacillus. Ann. Alim. et Nutr., 1963, 17 (6), B 427.

[6] DUPUy (P.). Microorganismes résistant aux radiations ionisantes. Int. $J$. of Appl. Radiat. and Isotopes, 1963, 14, 29.

[7] Dupuy (P.) et Mocquot (G.). Développement de Lactobacillus dans le lait irradié. Int. J. of Appl. Radiat. and Isotopes, 1964, 15, 255.

[8] Fabre (R.), Cheymol (J.), Maguier de la Source (B.). Sur le contrôle des préparations thérapeutiques à base de ferments lactiques en vue de leur autorisation. Ann. Pharm. Fr., 1953, 11, 17.

[9] Gasser (F.). Identification des Lactobacillus fécaux. Ann. Inst. Pasteur, 1964, 106, 778 .

[10] Segliger (H. P. R.) et Werner (H.). Recherches qualitatives et quantitatives sur la flore intestinale de l'homme. Ann. Inst. Pasteur, 1963,105 (5), 911.

[11] Sharpe (F.). Toxinomie des Lactobacillus. Ann. Inst. Pasteur de Lille, $1961,133$. 